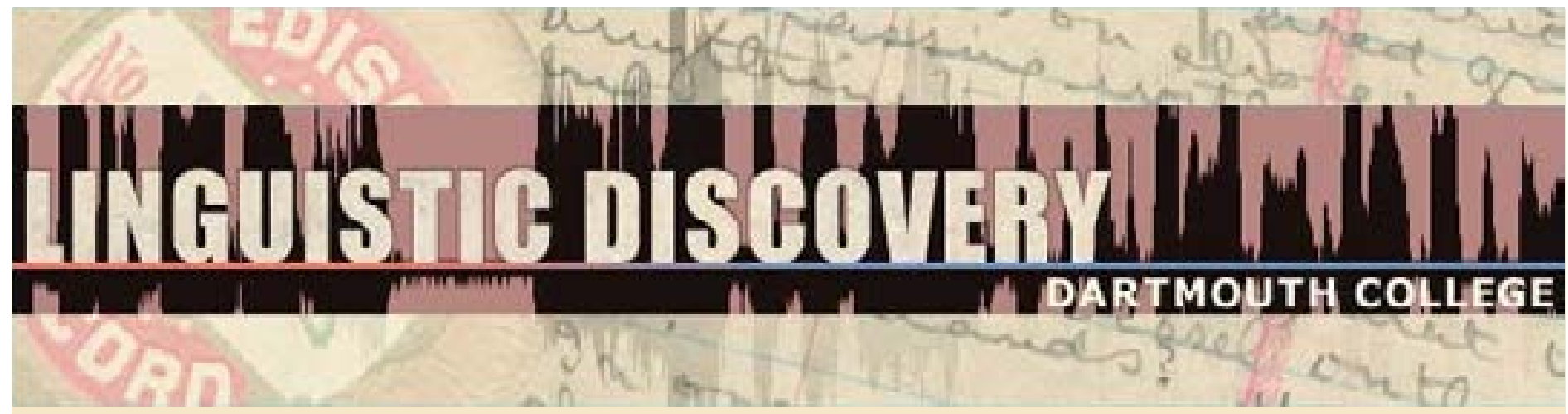

\begin{tabular}{|l|}
\hline Volume 10 \\
Issue 3 \\
2012 \\
\hline
\end{tabular}

\title{
Referential Effects on the Expression of Three-Participant Events across Languages - An Introduction in Memory of Anna Siewierska
}

Eva van Lier

University of Amsterdam

doi: 10.1349/PS1.1537-0852.A.413

url: http://journals.dartmouth.edu/cgi-bin/WebObjects/ Journals.woa/1/xmlpage/1/article/413

Linguistic Discovery

Published by the Dartmouth College Library Copyright to this article is held by the authors. ISSN 1537-0852 linguistic-discovery.dartmouth.edu 


\section{Referential Effects on the Expression of Three-Participant Events across Languages - An Introduction in Memory of Anna Siewierska Eva Van Lier \\ University of Amsterdam}

\section{Background of the Current Issue}

The majority of the papers collected in this special issue were presented at the Workshop on referential hierarchies in three-participant constructions, held at Lancaster University in May 2011. Two papers - on Yakima Sahaptin by Joana Jansen and on Araki by Alexandre François were not presented at the workshop, but originated in the same context: a research project on referential hierarchies in three-participant constructions, carried out by the workshop organizers: Anna Siewierska and myself, the guest editor of the current issue.

It was with great sadness that we, the authors of the papers collected here, heard of Anna's sudden death in a car accident in Vietnam, on August $6^{\text {th }} 2011$, just a few months after we had convened in Lancaster. I wish to dedicate this special issue to the memory of Anna, who was the principle investigator of the project that inspired its creation. I also wish to thank Lindsay Whaley, the editor of Linguistic Discovery, for giving me the chance to complete this issue in Anna's honor.

The project on referential hierarchies in three-participant constructions is part of a larger project on Referential Hierarchies in Morpho-Syntax (RHIM), which is in turn one of the EuroBABEL projects funded by the European Science Foundation. The EuroBABEL initiative promotes empirical research on endangered languages, with the aim of advancing our knowledge of linguistic structure in general. The funding of the workshop in Lancaster by the EuroBABEL organization is gratefully acknowledged.

I believe - and I am sure I can speak on behalf of Anna too - that the workshop in Lancaster and the current issue reflect fruitful collaboration in more than one respect. Most importantly, I am deeply grateful to the authors of the papers on endangered languages for the effort they have put into collecting first-hand data on the intricate details of referential effects in three-participant constructions, and for their willingness to share their expertise with Anna and me. At the same time, I think that our cross-linguistic perspective has helped colleagues working on individual languages to ask questions that otherwise might have remained unanswered. This crossfertilization has been indispensable for the development of our understanding of the theory and typology of referential effects on three-participant constructions.

The current issue contains contributions on languages from different geographical and genetic backgrounds. Many of these are languages studied by members of the RHIM project (this holds for Blackfoot, Yakima Sahaptin, and Movima), but a second EuroBABEL project on AlorPantar languages is also represented (see the paper by Marian Klamer and Antoinette Schapper). In addition, the projects on endangered languages have inspired further investigation of an extremely well-studied language like Spanish (see the paper by Chiyo Nishida).

This introductory paper outlines some of the theoretical and typological notions that constitute the common ground behind the case studies collected in this issue. This common ground is situated at the intersection of two research domains: referential hierarchies and threeparticipant constructions. First, in section 2, I discuss referential conditions on argument coding 
from the general perspective of alignment in one- and two-participant constructions. I also consider the additional conditioning factor of lexical predicate class. Sections 3 to 6 are specifically concerned with three-participant constructions; their definition (section 3), referential effects on their argument encoding (section 4), and interaction with lexical factors (section 5). The overview on three-participant constructions is rounded off with a brief summary (section 6). Finally, in section (7) I introduce the individual papers that constitute the body of this issue.

\section{Referential and Lexical Conditions on Argument Coding}

Ever since Silverstein (1976), the effects of referential properties on argument realization have been widely studied (for an overview see for instance Witzlack-Makarevich 2011, chapter 6). From the perspective of the current issue, two aspects of such referential effects are of particular importance.

First, there is a range of different types of referential properties, each of which involves several different values. These values can be hierarchically ordered with respect to each other, in terms of how they affect argument encoding, as represented in (1): ${ }^{1}$
(1) a. pronoun $>$ noun
b. proper noun $>$ common noun
c. $\quad 1^{\text {st }} / 2^{\text {nd }}$ person $>3^{\text {rd }}$ person
d. human $>$ non-human animate $>$ inanimate
e. $\quad$ specific $>$ non-specific referential $>$ generic/non-referential
f. definite $>$ indefinite
g. $\quad$ singular $>$ plural
h. topical > non-topical

Notably, the referential factors in (1a-h) are not homogeneous; they reflect inherent categories (e.g. humanness), syntactic categories (e.g. (pro)nominality) and discourse-related categories (e.g. topicality). Nonetheless, (some of) the individual hierarchies have been presented in integrated or nested fashion. Also, both separated and combined versions of hierarchies have featured in the literature under a variety of names (see e.g. Bickel 2010: 410 and Witzlack-Makarevich 2011: 89 for examples and references). Here I will use the general term referential properties to refer to the factors and their values listed in (1), and the term referential effects to refer to the way(s) in which these properties affect argument encoding.

Concerning the specific form that referential effects may take, several predictions have been formulated in the literature. For case marking, it has been hypothesized that referentially highranking agents and low-ranking patients have higher chances of being zero-marked (Comrie 1989). According to an alternative interpretation, this prediction concerns distributionally unmarked nominative and absolutive case forms: high-ranking participants are expected to show nominative alignment, and low-ranking participants to show absolutive alignment (Silverstein 1976). However, recent testing of these predictions against large typological data sets provides only weak statistical support (see Bickel 2008, Bickel \& Witzlack-Makarevich 2008).

\footnotetext{
${ }^{1}$ These hierarchies have been proposed in e.g. Croft 1990, Dixon 1994, Aissen 2003, Siewierska 2004, de Swart 2007.
} 
As for agreement marking, it has been predicted that referentially high-ranking participants are more likely to trigger agreement than low-ranking participants. While this expectation is born out for agents, this is not the case for patients, which may also show the reverse pattern, at least as far as the factor of person is concerned (Siewierska 2004: $149 \mathrm{ff}$ ).

In general, however, the common principle behind referential effects, and behind the hierarchies in (1a-h) appears to be the following: if grammatical relations in a certain language have restricted access depending on referential properties, then participants with referential properties on the high (i.e. left) end of the hierarchies in (1) are more likely to have such access than participants with lower-ranking properties (i.e. more to the right in (1)) (Bickel 2008, 2010). At the same time, individual languages and constructions will vary as to exactly which referential properties are relevant.

A second issue of particular relevance to the theme of the current issue is how referential restrictions are 'applied' in a particular construction of a particular language; more specifically, whether argument realization is determined on the basis of the referential properties of a single participant, or whether the properties of two (or more) participants must be taken into account. The former case is typically referred to as differential marking. It has been discussed mostly in the context of (dependent) marking of patient arguments, commonly known as differential object marking (Bossong 1985, Aissen 2003), but it is relevant also for other types of argument encoding, namely differential subject marking (DeLancey 1991, Dixon 1994, de Hoop \& de Swart 2009), differential recipient/goal marking (Haspelmath 2007, Kittilä 2008), and differential theme marking (Haspelmath 2007, Malchukov 2008).

In contrast to differential marking, which is based on the properties of a single participant, argument realization may be co-argument conditioned, i.e. dependent on the referential properties of more than one participant. ${ }^{2}$ A specific constellation of multiple participants with certain referential properties is called a scenario (following Zúñiga 2006, Bickel 2010). The classical example of co-argument conditioned marking is a system that has been termed hierarchical alignment or, more specifically, hierarchical agreement (Nichols 1992, Siewierska 2004). It involves competition between two participants for a specific type of morpho-syntactic treatment; typically indexation by means of verbal inflection. The participant with the highestranking referential properties wins this competition, regardless of its role. Additional marking on the verb can indicate whether the action proceeds from a higher to a lower-ranking participant (direct) or from a lower to higher-ranking one (inverse). This type of system is attested for instance in the Algonquian language Blackfoot (see Russell et al., this issue).

However, there are many other variants of co-argument conditioned marking systems, as is evident from almost all the papers in the present issue. It is important to realize that not all of these systems are hierarchical in the sense that argument realization is based on the relative referential properties of two participants, with the higher one outranking the lower one. It is also possible that the marker used to encode a specific argument varies depending on the nature of its co-argument, without involving competition for the same marker. As argued by WitzlackMakarevich and colleagues (2011), the crucial characteristic of co-argument conditioned alignment resides in its being based on the properties of more than one argument, and classical hierarchical systems represent just one of multiple options in this domain.

From the perspective of alignment typology, referential effects present a challenge: there is no straightforward way to compare argument realization across one-, two-, and three-participant constructions in order to determine basic alignment patterns, since the encoding of $\mathrm{S}, \mathrm{A}, \mathrm{P}, \mathrm{T}$,

\footnotetext{
${ }^{2}$ The term co-argument conditioned alignment is proposed by Witzlack-Makarevich et al. (2011).
} 
and $\mathrm{G}$ roles (to be defined below) depends on referential factors. For splits in the form of differential marking, the solution would be to compare only participants with the same referential values. However, this is impossible in the case of co-argument conditioned argument realization, where the encoding of each argument-type can only be defined in terms of its co-occurrence with another argument-type. Witzlack-Makarevich et al. (2011) propose to solve this problem by cross-comparing argument realization in all possible scenario types and calculating proportions of scenarios that display specific alignment patterns.

The same line of research addresses a similar problem associated with a different type of condition on argument coding: lexical predicate class (see Bickel et al. 2010). In many languages, individual predicates show different argument realization frames. Again, the question arises as to how this variation can be accounted for in alignment typology. A frequently practiced solution is to determine alignment patterns on the basis of 'default' predicate classes in a particular language (see Haspelmath 2011). However, apart from the fact that it is not straightforward which criteria should be used to determine such default classes, this approach boils down to ignoring an important part of the attested variation: the behavior of all the non-default predicate classes. Therefore, Bickel and colleagues use a method that is related to the one proposed for coargument conditioned systems: they compare argument realization across different types of lexical classes, and calculate alignment patterns proportionally.

In sum, typological investigations of referential and lexical effects on argument realization reveal a wide range of diversity. In particular, to compare the expression of arguments across different constructions in specific languages one must take into account (i) the referential properties of these arguments and potentially also of their possible co-arguments, and (ii) the specific lexical predicates or predicate classes involved. The following sections will show how the challenges that arise in the analysis of one- and two-participant constructions (the basic constructions involved in alignment theory and typology) are relevant for three-participant constructions as well.

\section{Definition of Three-Participant Constructions}

For the purpose of the current issue, a three-participant construction is defined as a construction that expresses a three-participant event, which is in turn defined by Margetts and Austin (2007: 397) as a "dynamic state of affairs that crucially involves three entities in its conceptualization". It should be noted that this definition is wider than the one employed by Malchukov et al. (2010:1), who restrict their scope to ditransitive constructions, which involve an agent, a theme (T), and recipient-like (R) argument. Even though the latter definition includes some "less central" recipients, like the addressee of mental transfer verbs (such as 'show' and 'tell'), it excludes other types of three-participant constructions such as those in which the third participant is a spatial goal rather than a recipient, as with events of putting. While the latter type of three-participant constructions are included in the definition employed here, this does not mean that all papers in the current issue cover the same broad range of construction types. Some indeed include event-types like putting, but others focus on construction types corresponding to ditransitive constructions as defined by Malchukov and colleagues.

Our definition of three-participant constructions is in keeping with the semantic approach to argumenthood proposed by Bickel and Nichols (2009) and Bickel (2010). In this approach, generalized argument roles are defined, firstly, in terms of the number of participants implied by the meaning of the verb. Thus, $\mathrm{S}$ is the sole argument of a one-participant verb. If the event 
expressed by the verb implies the involvement of more than one participant, the relevant argument roles are distinguished as follows: $\mathrm{A}$ is the more agent-like argument and $\mathrm{P}$ the less agent-like argument of a two-participant verb. With three-participant verbs, the $\mathrm{T}$ argument corresponds to the transferred or moved participant, while $\mathrm{G}$ is the participant towards which the transfer action is directed.

Notably, since some of the papers in this issue restrict their discussion to three-participant events that involve a recipient-like G argument (and don't take into account other types of Gs, such as locational goals), these papers employ R instead of G, where R can be regarded as a subtype of the generalized G-role. In addition, there is some variation between the papers with respect to the term used for the less agent-like argument of a two-participant verb, which is sometimes referred to as $\mathrm{O}$ rather than $\mathrm{P}$, following the Dixonian tradition. Unlike the $\mathrm{G} / \mathrm{R}$ variation, however, the $\mathrm{P} / \mathrm{O}$ alternation is just a matter of notational convention. ${ }^{3}$

Since the 1980's (Dryer 1986; Croft 1990; Siewierska 2003, 2004, Haspelmath 2004, 2007; Malchukov et al. 2010), three-participant constructions have been included in alignment theory and typology (although in various terminological guises). The basic ditransitive alignment patterns represented in (2), together with their intransitive/monotransitive counterparts, are in current use and are referenced in this issue. Note that the term ditransitive alignment is not meant to imply that these alignment types are applicable only to ditransitive constructions as defined by Malchukov et al. (2010). Rather, these alignment types are applicable to three-participant constructions in general, but I will nonetheless use the term ditransitive alignment as a convenient short hand.

(2)

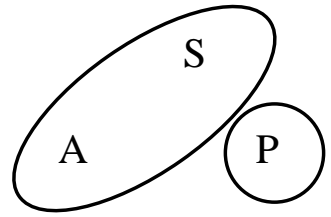

Accusative

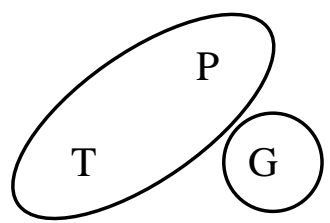

Indirective
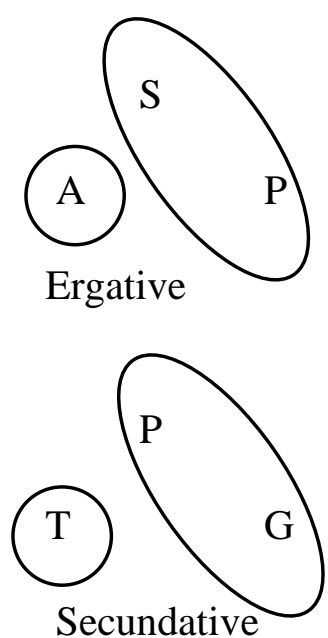

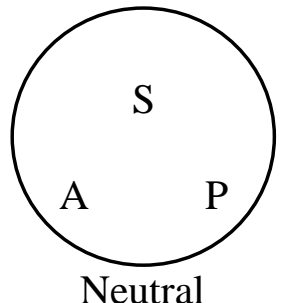

Neutral

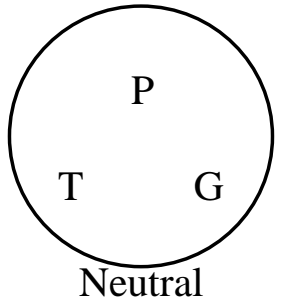

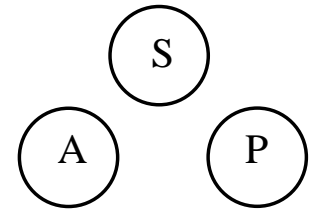

Tripartite

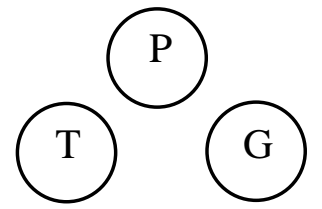

Tripartite

\footnotetext{
${ }^{3}$ See Haspelmath (2011) for a discussion of different types of approaches to the terms $\mathrm{S}, \mathrm{A}, \mathrm{P} / \mathrm{O}$ and G/R as used in descriptive and comparative research. As mentioned, I follow the "Bickelian" approach here.
} 


\section{Referential Effects on Three-Participant Constructions}

Referential effects on argument realization and alignment in three-participant constructions have been studied from cross-linguistic and language-specific perspectives. In general, however, this topic has received relatively little attention, probably because most ditransitive constructions (as defined by Malchukov et al. 2010; see above) involve $\mathrm{T}$ arguments that rank low on the referential hierarchies listed in (1) above, while $\mathrm{R}$ arguments tend to rank high. This holds specifically for ditransitive verbs of the 'give' type, which have dominated research in threeparticipant constructions from the lexical side. Nonetheless, there are a number of exceptions to these biases, which I will briefly review in the remainder of this section.

Firstly, three-participant constructions with referentially high-ranking Ts have been studied often from generative and alternative formal perspectives - in relation to the so-called Person Role Constraint (see e.g Perlmutter 1971; Bonet 1994; Anagnostopoulou 2003; Ormazabal \& Romero 2007). In the Romance languages, where this was first noted, the constraint defines a dis-preference for $1^{\text {st }}$ or $2^{\text {nd }}$ person $\mathrm{Ts}$, which is formally reflected by the use of a relatively complex prepositional construction (as in $3 a$ ), rather than a sequence of two clitics (as in $3 b$ ):

French (quoted in Haspelmath 2004: 2)

$\begin{array}{ll}\text { Agnès } & \text { me } \\ \text { Agnes } & 1 \text { SG.ACC }\end{array}$

presenterá

'Agnes will introduce me to her.'

b.

$\begin{array}{llll}\text { Agnès } & \text { me } & \text { la } & \text { presenterá } \\ \text { Agnes } & \text { 1SG.DAT } & \text { 3SG.FEM.ACC } & \text { introduce.FUT.3sG }\end{array}$

'Agnes will introduce her to me.'

Cross-linguistic research (Haspelmath 2004) shows that the Person Role Constraint is not restricted to the scenario represented in $(3 \mathrm{a})$ - where the $1^{\text {st }}$ person T outranks the $3^{\text {rd }}$ person $G$ on the referential hierarchy of person (see (1c) above) - but in some languages also obtains when $\mathrm{T}$ and $\mathrm{G}$ have equal ranking, i.e. when they are both $3^{\text {rd }}$ persons or both speech act participants ( $1^{\text {st }}$ or $2^{\text {nd }}$ persons). In other languages the constraint is shown to extend beyond the person hierarchy, and to ultimately reflect a general preference for $\mathrm{G}$ to have higher-ranking referential properties than T. ${ }^{4}$ Notably, this constraint takes into account the relative referential properties of $\mathrm{T}$ and $\mathrm{G}$, and as such relates to co-argument conditioned marking. Drawing the parallel with coargument conditioned marking in monotransitive constructions, Haspelmath (2007) uses the term inverse ditransitive patterns for the expression of scenarios in which the referential properties of $\mathrm{T}$ and $\mathrm{G}$ go against the expected pattern of $\mathrm{G}$ outranking $\mathrm{T}$.

Closely related to Haspelmath's work is Kittilä's (2006) study on three-participant constructions involving two human non-agents. However, rather than taking the perspective of discourse frequency, Kittilä focuses on the distinguishability of the $\mathrm{T}$ and $\mathrm{G}$ roles, in relation to different types of non-agent encoding strategies employed by individual languages. In particular,

\footnotetext{
${ }^{4}$ I skip here the various formal explanations that have been offered for the Ditransitive Person Role Constraint; Haspelmath (2004) provides an overview of these.
} 
if a language displays an object-based or animacy-based strategy, this potentially gives rise to ambiguity: a human $\mathrm{T}$ and a human $\mathrm{G}$ would be coded in the same way, either by virtue of their being objects or because of their being human. This potential formal ambiguity can be resolved in different ways, such as the use of a prepositional construction, parallel to what we saw in French in (3a) above. In contrast, there are also languages that use a role-based marking strategy. In these languages $\mathrm{T}$ and $\mathrm{G}$ are always marked distinctly - independently of objecthood and referential properties - because they have different semantic roles. In these languages no ambiguity arises when $\mathrm{T}$ and $\mathrm{G}$ are both human, and therefore no special formal measures are expected.

The findings of Haspelmath's and Kittilä's studies are broadly confirmed in the work by Siewierska and Van Lier (2012a, b). Using a combination of corpus data and cross-linguistic questionnaires, they investigate the expression of three-participant events with two human nonagents ( $\mathrm{T}$ and $\mathrm{G}$ ) within and across different languages. They find (very) low frequencies of relatively high-ranking Ts, and morpho-syntactic repercussions of this non-prototypicality in the form of relatively more complex and otherwise deviant expression strategies. ${ }^{5}$ As for ambiguity avoidance, it is shown that while languages with role-based (as opposed to object-based or animacy-based) marking display fewer formal effects of non-prototypical scenarios, this does not mean that such effects are completely absent. This suggests that both discourse infrequency and ambiguity-avoidance play a role in explaining the attested variation. Furthermore, Siewierska and Van Lier point out lexical effects on the expression of (non-prototypical) three-participant events; a topic to which I return in section 5.

Apart from co-argument conditioned coding in three-participant constructions, several studies have considered the referential properties of $\mathrm{T}$ or $\mathrm{G}$ in isolation, and the effects of these properties on argument realization. As far as G is concerned, Haspelmath (2007) and Kittilä (2008) both investigate the cross-linguistic expression of different referential types of Gs. However, as with co-argument conditioned argument realization, they take slightly different perspectives and offer slightly different explanations for the attested patterns. According to Haspelmath (2007: 83) "special R-marking is more likely, the lower the $\mathrm{R}$ is in the animacy, definiteness, and person scales". Such special marking involves "indirective or dative" marking, and is interpreted as a formal reflex of the non-prototypicality (i.e. discourse infrequency) of Rs with low-ranking referential properties. A parallel argumentation is proposed for special marking of high-ranking Ts, even though this phenomenon is claimed to be much less frequently attested across languages.

While Haspelmath investigates whether specific referential properties trigger special Rmarking, Kittilä (2008) investigates different ways of coding animate as opposed to inanimate Gs, in comparison to animate and inanimate Ps. In two out of the three types of coding patterns distinguished in Kittilä's study, animate Gs are expressed in the same way as animate Ps. Therefore, he explains both differential G-marking and differential P-marking in terms of affectedness: the equal marking of animate Ps and Gs reflect their status as the primary affected targets in two- and three-participant events, respectively. This marking contrasts with the encoding of inanimate Gs, which are rather expressed as obliques. Kittilä's third type of coding system also involves oblique marking of inanimate Gs, but this does not contrast with "core" marking of animate Gs, since this type of system always encodes Ps differently from Gs. In sum,

\footnotetext{
${ }^{5}$ One such "deviant" pattern relates to the ordering of the $\mathrm{T}$ and $\mathrm{G}$ with respect to each other. Further cross-linguistic evidence for referential effects on constituent order in three-participant constructions can be found in Siewierska \& Bakker(2007), Heine \& König (2010), and Schnell (this issue).
} 
while the cross-linguistic data presented by Haspelmath and Kittilä are compatible, their distinct respective foci are reflected in the different types of functional explanations they propose.

In parallel with the previous section, this brief review of studies about referential effects on argument realization and alignment in three-participant constructions outlines a broad spectrum of variability. As Malchukov et al. (2010: 7) remark, "the identification of ditransitive alignment pattern requires that we identify a major monotransitive construction so that we know what the monotransitive $\mathrm{P}$ is that we compare the ditransitive $\mathrm{T}$ and $\mathrm{R}$ with. This is not straightforward if there is a major split in the coding of monotransitives." Malchukov and colleagues choose to "adopt the most typical transitive construction, with an inanimate, indefinite $\mathrm{P}$ as the major monotransitive construction".

This approach, however, is problematic. Firstly, it is not straightforward to choose a specific referential type of $\mathrm{P}$ as the standard of comparison. The same holds for $\mathrm{T}$ and $\mathrm{G}$ to the extent that each may have various referential properties, along several referential dimensions. Second, we have seen that the encoding of $\mathrm{P}, \mathrm{T}$, and $\mathrm{G}$ may depend not only on the referential properties of each of these participants considered in isolation, but also on the properties of their co-arguments. More generally, comparing the prototypical three-participant scenario (involving a low-ranking $\mathrm{T}$ and a high-ranking $\mathrm{G}$ ) with the prototypical two-participant scenario (involving a high-ranking A and a low-ranking P) leads to the exclusion of a large proportion of the attested variation.

This is especially true for the type of languages that are at the focus of attention in the present issue, namely those in which argument realization is primarily conditioned or at least pervasively influenced by referential factors. In addition, it would seem that three-participant constructions have a special potential for co-argument conditioned argument marking to come into play, as there are two non-agentive participants that may compete for (a certain type of) P-like morphosyntactic treatment. As Bickel and Witzlack-Makarevich show, the solutions proposed for parallel problems with the determination of alignment in one- and two-participant constructions (see section 2) are applicable to three-participant constructions as well (Bickel et al. 2010, Witzlack-Makarevich et al. 2011). This holds not only for referential effects, but also for lexical effects, to which I turn in the next section.

\section{Three-Participant Constructions and the Lexicon}

A second important source of variation in three-participant constructions is lexical predicate class. In fact, the lexical factor appears to be relatively strong in three-participant constructions, as compared to two-participant constructions: "While all languages have a substantial class of transitive verbs that behave uniformly, some languages have only a handful of ditransitive verbs, and not uncommonly these do not behave uniformly" (Malchukov 2010:2). Moreover, the lexical factor becomes increasingly prominent with the wider definition of three-participant constructions employed here.

Within the domain of lexical effects on argument encoding, a distinction can be made between splits and alternations. The former term refers to the 'purely lexical' phenomenon that a certain groups of verbs in a specific language selects one type of argument expression frame while another verb class selects another. The term alternation is used, by contrast, when the same lexical verb - or class of verbs - can occur with more than one argument expression frame.

With alternations, the choice for one or the other construction is influenced by multiple factors; among them referential factors of the type discussed above. Bresnan and colleagues (2007 and later work) extensively studied the dative alternation in English, using corpus data. 
The application of multiple-regression modeling allows these authors to assess the relative contribution to construction choice of a number of referential factors, including definiteness, animacy, and anaphoricity, which show pervasive partial correlations. This method also allows teasing apart the effects of referential factors on the one hand - specifically anaphoricity and topicality - and heaviness or relative complexity of the $\mathrm{T}$ and $\mathrm{G}$ arguments on the other hand (cf. Wasow 2002).

Another condition on the choice between alternating argument realization frames concerns the different semantic meanings associated with specific construction types. For the English dative alternation, it has been proposed that the double object construction expresses caused possession meaning, while the prepositional construction has caused motion semantics (Goldberg 1995). More recently however, Rappaport Hovav and Levin (2008), have argued that whether the dative alternation has a semantic impact or whether it is rather referentially determined depends on the particular verb. Specifically, 'send'-type verbs are claimed to have caused possession meaning only when they occur with the double object construction and caused motion meaning when they occur with the prepositional construction. In contrast, 'give'-type verbs have caused possession meaning in both construction types. With these latter verbs, the dative alternation is triggered by factors of the type identified by Bresnan and colleagues.

Further corpus-based research on the dative alternation - e.g. Gries and Stefanowitsch (2004) for English and Colleman (2009) for Dutch - points to differences between individual verbs in terms of constructional preferences, i.e. whether a specific alternating verb occurs significantly more often in one or the other construction. Colleman (2009) focuses on semantic factors influencing such preferences in Dutch, suggesting that certain verbs are more strongly oriented towards the effect of the action on the G-participant, whereas other verbs are T-oriented. This semantic principle potentially cross-cuts other semantic classifications of three-participant verbs (cf. Levin 1993). For instance, within the class of communication verbs in Dutch, the verb aanraden 'advise' is arguably most concerned with the effect of the action on the addressee $(\mathrm{G})$, whereas bekendmaken 'announce' is more about a change in the state of $\mathrm{T}$. This difference would explain why aanraden typically occurs in the double object construction, while bekendmaken is found most often with the prepositional construction.

Malchukov et al. (2010: 20) interpret this type of semantic difference in terms of the affectedness of the $\mathrm{T}$ and $\mathrm{G}$ argument, respectively. Since affectedness and referential factors like animacy typically co-vary, we see again that different factors conditioning alternations are easily confounded. In other words, the constructional preferences of specific lexical verbs may be (partially) caused by the referential properties of the participants that these verbs tend to cooccur with. In a recent attempt to assess this problem, De Swart, Van Bergen and Van Lier (2011) conducted a production experiment in Dutch, involving alternating verbs with different constructional preferences (based on Colleman's (2006, 2009) corpus data), combined with identical scenarios, i.e. with the same sets of referential T/G-types. The results of this study indicate that constructional preferences of individual lexical verbs exist independently of the referential properties of non-agentive participants.

Another point that emerges from research on the dative alternation concerns micro-level lexical differences, both between languages and within languages. Colleman's work mentioned above (2009: 693) shows that while semantic factors driving the alternation in English and Dutch are grosso modo the same, this does not mean that translational equivalents in these two languages display the same constructional behavior. Looking at alternation within a single language, Ormazabal and Romero (2007) remark that Spanish enviar and mandar - both verbs 
meaning 'send' - pattern differently with respect to the use of two clitics, as opposed to a prepositional construction: in scenarios with two human pronominal non-agents, two clitics are more widely used with enviar than with mandar (see also Nishida, this issue, for micro-level lexical effects in Spanish).

Lexical effects concern not only constructional choice with alternating verbs, but also involve altogether distinct verb classes. In the latter case, we are dealing with lexical splits. Malchukov et al. (2010: 48ff) investigate general patterns of lexical splits across languages, trying to find out whether it is "possible to establish a predisposition of semantic verb classes for specific alignment patterns [and to] make predictions concerning how a verb with a particular meaning will pattern cross-linguistically". Their results show patterns of identical marking of certain three-participant event-types, as expressed by individual lexical verbs. For instance, if allative marking is used for the G-role in prototypical ditransitive constructions of the 'give' type, then this marking extends to verbs of caused motion, such as 'send' and 'throw'.

Just like construction alternations, lexical splits show both macro- and micro-level variation. While Malchukov and colleagues identify broad cross-linguistic patterns, there are also subtle differences between closely related languages and between verb classes in a single language. For example, Siewierska and Van Lier (2012b) find that certain English verbs that occur relatively frequently with two human non-agents (such as introduce) belong to the class that combines exclusively with the prepositional construction. In Dutch, the translational equivalents of these verbs (such as voorstellen) rather belong to the alternating class, even though in scenarios with two human non-agents the double object construction is systematically avoided.

Further examples are provided by the studies in the current issue: in some languages apparently near-synonymous verbs belong to different predicate classes with distinct alignment patterns. Blackfoot, for instance, has two verb stems meaning 'give', ohkot- and omatska-, of which the former always indexes $\mathrm{G}$, while the latter indexes only $\mathrm{T}$ (see Russell et al., this issue). Similarly, in Movima we find one verb 'ask' $d a j<a$ : $>w a$ with secundative alignment and another verb 'ask' daja:ja with indirective alignment (see Haude, this issue). Arguably, as was the case with alternating verbs, these lexical splits are motivated in terms of whether the verb meaning highlights the affectedness of $\mathrm{G}$ or $\mathrm{T}$.

A final locus of lexical variation, which is not taken into account in the typological overview by Malchukov et al. (2010), involves derived three-participant constructions, more specifically applicative and causative constructions. It is often assumed that the applied participant and the causee are morpho-syntactically treated like a monotransitive P (Peterson 2007). However, several papers in this issue show that there may well be differences in argument structure and alignment, not only between different types of derived three-participant constructions but also between derived and un-derived three-participant constructions (see e.g. Rose; Jansen; Russell et al.; Haude, all this issue).

\section{Three-Participant Constructions - Summary and Outlook}

The previous sections discussed how the encoding of three-participant events is conditioned by a variety of factors. Among these, referential factors constitute the focus of attention of the present collection of papers. However, these referential factors interact with other factors, including the semantic (micro-)roles of different event types, as expressed by individual lexical verbs belonging to specific verb classes. These lexico-semantic factors are in their turn intertwined 
with formal factors such as specific argument-marking strategies, and with functional factors such as frequency, analogy, and transparency.

The discussion in the previous sections makes clear that issues arising in studies on intransitive/monotransitive alignment and argument realization are relevant for three-participant constructions as well. At the same time, these issues need to be assessed independently. More specifically, the data presented in this special issue - very briefly summarized in the final section of this introduction - shows that referential effects on argument realization in one- and twoparticipant constructions of a particular language do not directly carry over to three-participant constrictions in that language. ${ }^{6}$ The possible mismatches are of several types: the nature and number of the relevant referential factors may differ; the relative ranking of referential factors and of individual referential values may differ; the way in which referential factors are applied may differ (i.e. the referential effect may be of the differential versus the co-argument conditioned type); and - of course - the formal effects may differ.

Finally, it is worth pointing out that corpus-based and experimental research, of the type carried out for English and Dutch, is still restricted in endangered languages, for which both data base sizes and speaker numbers are comparatively limited. Consequently, explanations based on patterns of usage frequency and processing are in need of empirical support from more and more diverse languages. The studies collected in this issue represent very promising steps towards achieving this goal.

\section{The Papers Collected in This Issue}

\section{Françoise Rose on Mojeño Trinitario, an Arawakan language of Bolivia}

Mojeño Trinitario has co-argument conditioned indexation in monotransititive constructions: the form used to index $\mathrm{A}$ depends on whether $\mathrm{P}$ is a $3^{\text {rd }}$ person or speech act participant $\left(1^{\text {st }}\right.$ or $2^{\text {nd }}$ person). The paper compares three types of three-participant constructions: underived 'give'-type constructions, and two types of derived constructions: causatives and applicatives. The first two types are shown to display an alternation between neutral and indirective alignment determined by a person-hierarchy (SAP>3), to the extent that only SAPs can be indexed on the verb. In addition, underived and causative (but not applicative) constructions both provide evidence for construction-specific alignment, each in a slightly different way.

\section{Joana Jansen on Yakima Sahaptin, a dialect of the Sahaptin language spoken in the Pacific Northwest of the United States}

The structure of monotransitive constructions in Yakima Sahaptin is heavily dependent on referential factors. Both case marking of $\mathrm{A}$ and indexation of $\mathrm{A}$ and $\mathrm{P}$ are co-argument conditioned, involving the factors of person and topicality. Animacy determines differential case marking of P. The paper describes the effects of these referential factors on the encoding of a range of three-participant constructions, involving three underived verb classes and two derived constructions. Construction alternation, in the form of competition between $\mathrm{T}$ and $\mathrm{G}$ for object status is found with 'give'-type verbs and with causatives. Three-participant constructions involving other verb classes display either indirective or secundative alignment.

\footnotetext{
${ }^{6} \mathrm{cf}$. Haspelmath (2005), who finds no correlation between monotransitive and ditransitive alignment.
} 
Lena Russell, Inge Genee, Eva van Lier, and Fernando Zúñiga on Blackfoot, an Algonquian language spoken in Southern Alberta (Canada) and Northern Montana (United States)

Algonquian languages are renowned for their strongly referentially determined grammatical systems, involving such factors as animacy, person, and topicality. Blackfoot represents a special case in that specificity plays a crucial role in argument encoding as well. In monotransitive constructions, verbal inflection - in the form of person indexation and direct-inverse marking is co-argument conditioned. The authors discuss the effects of referential factors on different types of derived and underived three-participant constructions. In addition, they identify interaction with lexical factors: some verbs allow both indirective and secundative alignment, and in this case construction choice depends on the animacy of R.

\section{Katharina Haude on Movima, an isolate spoken in Amazonian Bolivia}

Movima has a system that resembles Blackfoot to the extent that monotransitive constructions are fully determined by the relative referential properties of $\mathrm{A}$ and $\mathrm{P}$, involving direct-inverse marking on the verb, although there is no agreement. The relevant referential factors involve person and topicality. Three-participant constructions can be indirectively or secundatively aligned: either $\mathrm{T}$ or $\mathrm{G}$ is treated like $\mathrm{P}$ and enters into the monotransitive direct-inverse marking system; the remaining participant is always encoded as an oblique. Interestingly, construction choice is fully lexically determined, and some verbs with seemingly very similar semantics exhibit different alignment patterns.

\section{Alexandre Françoise on Araki, an Oceanic language spoken on an island of the same name in Vanuatu}

In this language, the marking of monotransitive $\mathrm{P}$ is determined by the referential factors of humanness and anaphoricity, independently of the properties of A. In three-participant constructions, we find co-argument conditioned marking, depending on the relative properties of $\mathrm{T}$ and $\mathrm{G}$ and involving the additional referential factor of person. Moreover, we see a strong lexical factor at work, in the sense that the referentially determined construction alternation is specific to a single, three-member verb class, expressing prototypical transfer of physical or mental possession.

\section{Stefan Schnell on Vera'a, an Oceanic language of North Vanuatu}

Vera'a also has differential $\mathrm{P}$ marking, but the details of the relevant referential factors and values and the formal effects are different from those attested in Araki. This differential Pmarking is carried over to $\mathrm{T}$, and the flagging of $\mathrm{G}$ is also differential, depending on animacy. Within this indirective alignment pattern, however, there is variation in the order of $T$ and $G$, influenced by the relative anaphoricity and topicality of these participants. Finally, it is shown that indirective three-participant constructions are associated with caused motion; for the expression of caused possession Vera'a uses an adnominal construction that draws on two distinct types of possessive constructions. 


\section{Diana Schackow on Yakkha, a Kiranti language spoken in East Nepal}

Yakkha has co-argument conditioned agreement, and differential A-marking based on the factor of person. Concerning three-participant constructions, three verb classes are distinguished, each displaying a distinct basic alignment of case and agreement marking. One class in fact displays an alignment mismatch in the sense that case is neutral, but case agreement marking is secundative. Furthermore, there are several types of referentially determined construction alternations, which affect case and/or agreement marking. While the referential factors of person and animacy play a role in co-argument conditioned alternations, only animacy is relevant for differential case-marking of G. Finally, the Yakkha data show that individual verbs may select specific referential types of (non-agent) participants, allowing for instance animate Gs only or inanimate Ts only. When a verb disallows a referentially high-ranking $\mathrm{T}$, such an argument may still be introduced into the construction by means of verb serialization.

\section{Marian Klamer and Antoinette Schapper on Papuan languages spoken on the islands of Timor, Alor, and Pantar}

This paper adds a historical dimension to the present issue: it sketches the diachronic development of 'give' constructions in ten languages, starting from the observation that each of these languages synchronically employs two or three different construction types. While all of these constructions are secundatively aligned in terms of verbal indexation, they differ as to the encoding of $\mathrm{T}$, which is either bare or flagged in different ways. These flagging strategies are shown to stem from serial verb constructions of several types, and they display different degrees of grammaticalization.

\section{Chiyo Nishida on Mexican Spanish}

This paper uses frequency data from a written corpus, investigating an alternation pattern involving three-participant constructions with a prepositionally marked $\mathrm{G}$ argument, which may or may not be doubly expressed by means of a clitic. The results suggest that clitic doubling is restricted to referentially high-ranking $\mathrm{G}$ arguments, while constructions without doubling do not exhibit this restriction. In addition, more fine-grained distributional patterns can be discerned for individual lexical verbs.

\section{References}

Anagnostopoulou, Elena. 2003. The syntax of ditransitives: evidence from clitics. Berlin: Mouton de Gruyter.

Aissen, Judith. 2003. Differential object marking: Iconicity vs. economy. Natural Language and Linguistic Theory 21.435-483.

Bickel, Balthasar. 2008. On the scope of the referential hierarchy in the typology of grammatical relations. Case and Grammatical Relations: Studies in Honor of

Bernard Comrie, ed. by Greville G. Corbett and Michael Noonan, 191-210. Amsterdam: John Benjamins. 
-----. 2010. Grammatical relations typology. The Oxford Handbook of Language Typology, ed. by Jae Jung Song, 399-444. Oxford: Oxford University Press.

Bickel, Balthasar and Johanna Nichols. 2009. Case marking and alignment. The handbook of case, ed. by Andrej Malchukov and Andrew Spencer, 304-321. Oxford: Oxford University Press.

Bickel, Balthasar and Alena Witzlack-Makarevich. 2008. Referential scales and case alignment: reviewing the typological evidence. Scales, ed. by Andrej Malchukov and Marc Richards, 137. Leipzig: Institut für Linguistik.

Bickel Balthasar, Alena Witzlack-Makarevich, and Taras Zakharako. 2010. Alignment across the lexicon. Paper presented at Syntax of the World's Languages IV, Lyon, 23-26 September 2010.

Bonet, E. 1994. The Person-Case constraint: A morphological approach. The Morpho-syntax Connection. MIT Working Papers in Linguistics 22, ed. by Heidi Harley and Colin Philips, 33-52.

Bossong, Georg. 1985. Empirische Universalienforschung: differentielle Objektmarkierung in neuiranischen Sprachen. Tübingen: Narr.

Bresnan, Joan, Anna Cueni, Tatiana Nikitina, and Harald Baayen. 2007. Predicting the dative alternation. Cognitive Foundations of interpretation, ed. by Gerlof Bouma, Irene Krämer, and Joost Zwarts, 69-94. Amsterdam: Royal Netherlands Academy of Science.

Colleman, Timothy. 2006. De Nederlandse datief-alternatie (The Dutch dative alternation). $\mathrm{PhD}$-Thesis, Ghent Universiy.

-----. 2009. Verb disposition in argument structure alternations: a corpus study of the dative alternation in Dutch. Language Sciences 31.593-611.

Comrie, Bernard. 1989. Language Universals and Linguistic Typology. Chicago: University of Chicago Press, 2nd revised edition.

Croft, William. 1990. Typology and universals. Cambridge: Cambridge University Press.

DeLancey, Scott. 1981. An interpretation of split ergativity and related patterns. Language 57.626-657.

Dixon, Robert M. W. 1994. Ergativity. Cambridge: Cambridge University Press.

Goldberg, Adele 1995. Constructions: A Construction Grammar approach to argument structure. Chicago: University of Chicago Press.

Gries, Stephan and Anatol Stefanowitsch. 2004. Extending collostructional analysis. International journal of Corpus Linguistics 9.97-129.

Haspelmath, Martin. 2004. Explaining the Ditransitive Person-Role Constraint: a usage-based account. Constructions 2.1-49.

-----. 2005. Argument marking in ditransitive alignment types. Linguistic Discovery 3/1.1-21

-----. 2007. Ditransitive alignment splits and inverse alignment. Functions of Language 14/1.197102.

-----. 2011. On S, A, P, T and R as comparative concepts for alignment typology. Linguistic typology 15/3.535-567.

Heine, Bernd \& Christa König. 2010. On the linear order of ditransitive objects. Language Sciences 32/1.87-131.

de Hoop, Helen \& Peter de Swart (eds.) 2009. Differential subject marking (Studies in Natural Language and Linguistic Theory 72). Springer. 
Kittilä, Seppo. 2006. The woman showed the baby to her sister. On humanness-driven ambiguity in ditransitives. Case, valency and transitivity, ed. by Leonid Kulikov, Andrej Malchukov and Peter de Swart, 291-308. Amsterdam: John Benjamins.

----. 2008. Animacy effects on differential Goal marking. Linguistic Typology 12. 245-268.

Levin, Beth. 1993. English verbs and alternations: A preliminary investigation. Chicago: University of Chicago Press.

Malchukov, Andrej. 2008. Animacy and asymmetries in differential case marking. Lingua 118.203-221.

Malchukov, Andrej, Martin Haspelmath and Bernard Comrie. 2010. Ditransitive constructions: a typological overview. Studies in ditransitive constructions: A comparative handbook, ed. by Andrej Malchukov, Martin Haspelmath and Bernard Comrie, 1-64. Berlin: Mouton de Gruyter.

Nichols, Johanna 1992. Linguistic diversity in space and time. Chicago: University of Chicago Press.

Ormazabal, Javier and Juan Romero. 2007. The Object agreement constraint. Natural Language and Linguistic Theory 25/2.315-347.

Perlmutter, David, M. 1971. Deep and surface structure constraints in syntax. New York: Holt Rinehart and Winston.

Peterson, David A. 2007. Applicative constructions. Oxford: Oxford University Press.

Rappaport-Hovav, Malka and Beth Levin. 2008. The English dative alternation: The case for verb sensitivity. Journal of Linguistics 44.129-167.

Siewierska, Anna 2003. Person agreement and the determination of alignment. Transactions of the Philological Society 101/2.339-370.

-----. 2004. Person. Cambridge: Cambridge University Press.

Siewierska, Anna and Dik Bakker. 2007. Bound person forms in ditransitive clauses revisited. Functions of Language 14/1.103-125.

Siewierska, Anna and Eva van Lier. 2012a. Ditransitive construction with two human nonagentive arguments. Faits de Langues 39.141-156 (special issue on La saillance, ed. by Kathaina Haude and Annie Montaut).

-----. 2012b. Introduce : encoding a non-prototypical three-participant event across Europe. To appear in Argument Structure in Flux: The Naples/Capri Papers, ed. by Elly van Gelderen, Michaela Cennamo and Johanna Barðdal. Amsterdam: John Benjamins.

Silverstein, Michael. 1976. Hierarchy of features and ergativity. In Grammatical Categories in Australian Languages, ed. Dixon, Robert M. W., 112-171. New Jersey: Humanities Press.

de Swart, Peter. 2007. Cross-linguistic variation in object marking. Doctoral Dissertation, Radboud University.

de Swart, Peter, Geertje van Bergen and Eva van Lier. 2011. Lexical preferences in Dutch ditransitives. Poster presented at AMLAP 2011, Paris, 1-3 September 2011.

Wasow, Thomas. 2002. Postverbal behavior. Stanford: CSLI publications.

Witzlack-Makarevich, Alena. 2011. Typological Variation in Grammatical Relations. Ph D dissertation, University of Leipzig.

Witzlack-Makarevich, Alena, Taras Zakarkho, Lennart Bierkandt, and Balthasar Bickel. 2011. Decomposing hierarchical alignment: participant scenarios as conditions on alignment. Paper presented at SLE44, Logroño, 8-11 September 2011.

Zúñiga, Fernando. 2006. Deixis and Alignment: Inverse Systems in Indigenous Languages of the Americas. Amsterdam: John Benjamins 
Author's Contact Information:

Eva van Lier

Department of Linguistics

University of Amsterdam

Spuistraat 210

1012 VT Amsterdam, Netherlands

E.H.vanLier@uva.nl 